\title{
Improving Language Skills in the Teaching of Content Courses
}

\author{
A. Dzo'ul Milal \\ State Islamic University of Sunan Ampel Surabaya \\ a_milal@yahoo.co.id
}

\begin{abstract}
Divergent characteristics of subjects require different strategies of teaching and learning. Learning skill subjects such as listening, speaking, reading, and writing requires the learners to do more practical activities because the objective is to acquire language ability, whereas that of content subjects like Linguistics, Pragmatics, and Discourse Analysis demands that students do the activity of reading and understanding texts more because the goal is to get knowledge and understanding of the concepts. In so far as the students need both language ability and conceptual knowledge, teachers should design and implement comprehensive strategies by which students obtain not only knowledge about the concepts but also skill or ability in using the target language. This paper tries to describe and discuss such a strategy by which both targets are achieved.
\end{abstract}

Keywords ---- Teaching and learning strategies; skill and content courses; conceptual knowledge; language ability

\section{INTRODUCTION}

Teaching and learning strategy has become one of the concerns of experts in English Language Teaching (ELT) for years. To mention some of them are [1], [2], [3], [4], [5], [6], etc. Ideas and opinions to suggest various ways to increase the effectiveness of ELT are in continuous search. Strategies, methods, and techniques of language teaching and learning has been sustainably developed and appearing one after another such as Grammar Translation Method, Audiolingual Method, Direct Method, Suggestopedia, Total Physical Response, Communicative Language Teaching, Community Language Learning, etc. [5]. Despite such a steady development, however, there is no panacea in method. It means there is no one method which is the best for all conditions and situations.

Efforts and pursuit need always be made in order to find a strategy which can be regarded as appropriate to achieve certain objective. This paper is written in line with such a need.

There are basically two categories of English subjects prescribed in the curriculum of English Department, namely skill courses and content courses.
The skill courses are those of which objective is for the students to acquire the ability of communication using the target language both in spoken and written forms, in both productive and receptive modes. The examples of this type of courses are listening, speaking, reading, writing, grammar, pronunciation, and translation [7]. The second category, furthermore, is the content courses of which purpose is for the students to obtain knowledge and understanding of the conceptual ideas which are relevant with the subjects, for examples Linguistics, Pragmatics, Discourse Analysis, etc. [7]. In short, the main goal of the skill courses is the acquisition of language ability whereas the final goal of the content courses is the knowledge and understanding of conceptual ideas.

Such divergent objectives result in the differences of their characteristics which are manifested in terms of not only the materials but also the teaching and learning strategies as well as the evaluation systems which are implemented by teachers in classroom process. This paper tries to focus on the aspect of classroom strategies which integrate the differing characteristics so that the language skill which becomes the main purpose of skill courses is achieved while the teacher is teaching the content courses. In other words, this paper tries to reveal what classroom teaching and learning strategy implemented by the teacher is like so that students can improve their language skills while they are in the process of studying the content courses.

\section{THEORETICAL BASES}

The implementation of teaching and learning strategy in the classrooms is always based on the beliefs of the teacher about how learning takes place and how language is learned and/or acquired. The idea in this paper is underlain by the belief that language is best acquired by learners when it is used in frequent practice in real or authentic communicative situations. Such a belief goes in line with the principle of immersion by which learners are immersed in a situation where target language is richly exposed to 
and frequently used by the learners to carry out daily, natural activities.

According to Constructivistic belief (Piaget, 1976; Vygotzky, 1978), learning happens by the process of fulfilling the gaps between the present competence and the targeted competence. Learners need to be facilitated in order to develop their knowledge and/or ability through scaffolding to gradually proceed from being incompetent to being more competent. That is done by direct involvement of the learners in the experience of real social life.

In relevance with the learning of English as a foreign language, which becomes the focus of this study, in the effort of improving learners' English skills, teacher designed the classroom teaching and learning strategy of the content course, i.e. Discourse Analysis, in such a way that learners got the experience of real use of the target language while studying about the conceptual ideas and developing their knowledge about the course. In other words, the students' English ability is, hopefully, subconsciously constructed bit by bit through their direct use of the language in the receptive and productive activities while studying the concepts of Discourse Analysis.

In the view of Interactionism [8], moreover, it is believed that language is acquired as a result of interaction between internal aspect of human language capacity within the brain and the linguistic data from external environment outside the learners' selves. The interaction is in the form of comprehension. When the linguistic data are exposed to or perceived and understood by the learners, it indicates that there is an interaction between language and the learners' minds. In such a circumstance, language is successfully acquired and the learners' linguistic skill improves. On the contrary, when there is no interaction, due to either the absence of data or that of comprehension, acquisition is believed to fail.

That idea is in line with the Input Hypothesis [9] which says that language acquisition is effective when the learners are exposed to a sufficient quantity of comprehensible input. It implies that when the target language is used a lot in the learners' environment, and the learners can understand that target language data, their competence will improve. The corollary is that teacher should create the learning environment in such a way that students can perceive and understand a lot of target language uses, either by using it frequently or preparing various displays by which students can hear and read in most of their waking time. In that way, acquisition takes place effectively and learners' language ability improves.

In addition to comprehensibility, frequency is a factor that may affect acquisition [10]. It is claimed that when a certain grammatical item is more frequently used, that item is acquired better than other items less frequently used. Observations show that the more often the learners use the target language, the better their skill will be. In practice, furthermore, it is noticeable that those who live in a native language environment where the target language is daily used in their surroundings acquire the language faster than those who live in a non-native speaking country where the target language is barely used.

Another factor which may raise the effectiveness of learning process is the use of integrated human senses: visual, auditory, and physical modes. Relevant with this, [11] mentions the term Multimodality. The principle asserts that learning will be effective when it is done involving not only one mode, through only reading for instance, but also other modes, such as listening, speaking, and writing. It implies that when students do various activities involving their senses, such as reading and understanding the text, making its summary, writing its main contents, presenting the points orally, listening to peer's opinions, answering their questions, listening to lecturer's explanations, taking notes, and discussing, etc. the learning is more effective than just doing one kind of activity, e.g. only listening to lectures.

In sum, learning language skills will be effective when the teaching and learning strategy complies with the following principles:

1. Students are exposed to sufficient quantity of comprehensible input.

2. Students have low affective filter.

3. Students have strong learning motivation.

4. Students do frequent practice of using the target language.

5. Students practice authentic communication using the target language.

In consequence, in order to comply with those tenets, the pedagogical implications that need to be carried out by the teacher, among others, are:

1. Teachers use the target language.

2. The materials need to be interesting and relevant.

3. Students perform varied and fun activities.

4. Teacher should create low-anxiety learning condition.

5. The school environment is created input-rich.

6. Students do learner-active tasks.

\section{RESEARCH METHOD}

This is a reflective study in the sense that the description in this paper is made based on the experience of the writer as the experiencer of the phenomenon. The source of the data was the reflective experience of the researcher. The research site where the phenomenon being described took place was the classroom of the content course of Discourse Analysis for students of semester four, at English Department of the Faculty of Arts and Humanities, Sunan Ampel State Islamic University, Surabaya.

The main instrument was the researcher himself as the lecturer teaching the course. Being 
directly involved and present in the classroom activities, the writer was able to perceive the spirit as well as the dynamics of the class. As long as the whole semester, the researcher was able to observe and note the details of not only classroom activities including teaching and learning procedures and interaction patterns, but also the developments of students' competence including their confidence and their target language use.

The data were collected by jotting down some points which are relevant with the topic of this paper based on the researcher's personal perspective of his teaching experience. They were, then, analyzed by elaborating and describing the phenomenon, and finally the results were presented and discussed in conjunction with the theories of language learning and acquisition.

\section{FINDINGS}

This part presents the research findings relevant with the topic of the paper.

\section{A. Classroom Context}

The class where the research was conducted consists of about thirty two male and female, mixed ability, students. They belong to semester four of undergraduate program at the English Department (the second year of studying at university). In this term, they are taking both skill and content courses. The level of their English ability, in general, may be preintermediate in the sense that they have been able to handle oral and written communication for general purposes although still with effortful fluency and accuracy. They have already got some basic knowledge of Linguistics because they have taken Introduction to Linguistics as a pre-requisite subject to take Discourse Analysis [7].

\section{B. Teaching Subject}

All pedagogical subjects are intended to improve students' cognitive, affective, and practical/psychomotoric aspects of competence. The cognitive aspect includes the knowledge and understanding of concepts, ideas, and information which are relevant with the subjects. The affective aspect represents students' feeling and attitude in relevance with the knowledge they obtain. The practical aspect refers to students' ability to do something in relation with or in making use of their knowledge. Content courses emphasize more on cognitive aspect, whereas skill courses more on practical aspect.

In reference to the class under study, i.e. Discourse Analysis, its main objective is to enable students to understand some concepts in analyzing discourses in the forms of written and spoken texts and being able to analyze and produce discourses appropriately, effectively, and efficiently in natural or authentic communication contexts (Basic Course
Outline, 2016). The materials are mainly taken from Brian Paltridge's Discourse Analysis: An Introduction; Gillian Brown \& George Yule's Discourse Analysis; and Malcolm Coulthard's An Introduction to Discourse Analysis. The time allocated for this course was ninety to one hundred minutes per meeting. There were fourteen meetings along the semester.

\section{Teaching and Learning Strategy}

This part presents the medium of instruction and interaction, the interaction pattern of the participants, and the teaching and learning procedures.

\section{Medium of Instruction \& Interaction}

As a medium of instruction, English as the target language was maximally used. It means that the students presented the materials in English. Only when the students felt unable to get the meaning across in effective ways, they were allowed to use Indonesian, the teacher and students' native language, in one condition that its use should be kept minimal. In explaining the concepts and giving examples, the teacher also used English. Only when students felt to face difficulty to understand the concepts, the teacher may give some examples in Indonesian,

The medium of interaction between teacher and students during the class was English; however, communication among students was mostly Indonesian although the teacher had frequently reminded them to use the target language.

\section{Interaction Patterns}

The interaction patterns used in the teaching and learning process in the classroom were varied: Student - Students (S - Ss), Students - Student (Ss $\mathrm{S})$, Teacher - Students $(\mathrm{T}-\mathrm{Ss})$, and Students Teacher $(\mathrm{Ss}-\mathrm{T})$. The pattern was $\mathrm{S}-\mathrm{Ss}$ when one of the students gave oral presentation in front of his/her classmates. The pattern became $\mathrm{Ss}-\mathrm{S}$ when the members of the class were asking questions to the presenter about some incomprehensible or unclear points of the presentation. The pattern was $\mathrm{T}-\mathrm{Ss}$ when the teacher gave explanation to the class, and Ss - $\mathrm{T}$ when the students were asking questions to the teacher.

\section{Teaching \& Learning Procedures}

In the first meeting of the term, the teacher gave an overview of what the subject is about covering the objective, the materials, the main textbooks, the teaching and learning strategy, and the evaluation system. The main classroom teaching and learning strategy was basically comprised of students' oral presentation, discussion, and lecturing. On the first day of the term, students were divided into groups of two or three and each group was responsible to present one topic that had been selected. Prior to presentation, the members of each group should have 
made some preparation, as homework, by reading and understanding the topic, summarizing the contents, and making power point slides. The classroom procedures were as follows:

a) Members of the group submitted the written summaries to the teacher and then gave oral presentation of the topic to the class in turns. The class was listening.

b) The class members asked questions when they felt necessary and presenters responded to the questions by answering them directly and/or asking other students to suggest ideas and opinions.

c) Teacher re-clarified and re-explained either to reinforce the main points or to correct the points when the groups' presentation seemed unclear or incorrect while students were taking notes when necessary.

d) Students asked questions when they felt not to understand the points, and the teacher reclarified, re-explained, or gave more examples.

\section{DISCUSSION}

This part contains the discussion of the findings in relevance with the topic, i.e. in what ways the teaching and learning strategy of the content course conducted in the classroom enables the learners to improve not only their knowledge of concepts but also their English language skills.

The first point is dealing with the classroom context. Considering the number of students in the class, thirty two students might be too big to intensify the students' practice of using the target language in the classroom. Therefore, students were given tasks to be done outside of the class, such as reading and understanding the textbook, discussing its contents among the group members, writing the summary, and preparing the power point slides. In that way, students had more time to use and practice the target language more intensively. Hence, their reading, listening, speaking, and writing skills were practiced, and thus, improved.

The second factor is the teacher's maximal use of the target language as a medium of classroom instruction. When the teacher was explaining the concepts and giving examples using English, students were listening to him. In so far as the explanation and examples were within students' comprehension ability, their knowledge of the concepts of Discourse Analysis improved, target language acquisition occurred, and their language skills developed.

The third contributive element is the variety of interaction patterns. Variety is influential on maintaining students' interest and involvement in the learning process. By having the chance to present orally in front of their peers, to discuss the topic (asking and answering questions among themselves), students were stimulated to prepare themselves better; hence, they were able to attain greater impact on their memory. Speaking about the topic requires better comprehension and greater effort and thus, will be more memorable than just listening to it. This applied not only to their knowledge but to their language skill as well.

The fourth aspect is related to the classroom procedures of teaching and learning process. The fact that the students presented the selected topic orally preceded by individual reading, small group discussion, and writing the summary, was beneficial not only to increase self-confidence and strengthen their intellectual capacity, but also to improve integrated language skills (listening, speaking, reading, and writing). Students became accustomed to using the target language in both receptive and productive modes to carry out natural or authentic undertakings.

In addition, due to the fact that students are required to give oral presentation in front of the class members, students became more motivated to have good preparation prior to doing it because they wanted to perform well and did not want to look incompetent in the eyes of their peers. When they were wellprepared, presenters might also have the feeling of self-confidence; on the other hand, the audience felt relaxed and not on the defensive because they were addressed by their own classmates. According to the principle of language acquisition, input is effective when the learners have low affective filter [9]. In sum, the classroom strategy in term of students' giving oral presentation is beneficial not only for the presenters, but also for the other classroom members.

The fifth element contributing to the improvement of language skills is the classroom discussion which was led by the teacher. It started with teacher's explanation and exemplification of concepts. In so far as he was always using the target language, students were stimulated to using it for listening and understanding. That, by all means, reinforces the listening skill. When it was followed by discussion, students got the chance to practice using the target language to ask questions, to give comments, and to suggest ideas. Thus, they were drilled in conducting oral communication and interaction.

\section{CONCLUSION}

Students of English Department are in the need of improving not only their knowledge of concepts but also, more importantly, their language ability. To serve that purpose the curriculum prescribes both content and skill courses. Therefore, it is advisable that teachers design the classroom teaching and learning strategy of both kinds of subjects in such a way that students are assured to gain benefits to achieve both objectives. That is, among others, manifested by giving the students more chance to use the target language in both receptive and 
productive modes, in terms of spoken and written authentic communication.

\section{REFERENCES}

[1] Harmer. Jeremy, The Practice of English Language Teaching, London: Pearson Longman, 2007

[2] Spratt. Mary, Alan Pulverness, Melanie Williams, The TKT Course, Cambridge: Cambridge University Press, 2005

[3] Savignon. Sandra J, Communicative Competence: Theory and Classroom Practice, N.Y.: McGraw-Hill, 1997

[4] Finocchiaro. Mary B, Howard B. Altman, Penelope M. Alatis, The Second language classroom: directions for the 1980's, Oxford: Oxford University Press, 1997

[5] Richards. Jack C, \& Theodore S. Rodgers, Approaches and Methods in Language Teaching, Cambridge: Cambridge University Press, 1986

[6] Larsen-Freeman, Diane, Techniques and Principles in Language Teaching, Oxford: Oxford University Press, USA, 2000

[7] Anonymous, Curriculum of English Department at the Faculty of Arts and Humanities, UINSA Surabaya. Unpublished document, 2015

[8] Elli. Rod, Understanding Second Language Acquisition, Oxford: Oxford University Press, 2015

[9] Krashen. Stephen D, Second Language Acquisition and Second Language Learning, University of Southern California: Pergamon Press Inc, 1986

[10] Dulay, C. Heidi, Marina K. Burt, Stephen D. Krashen, Language Two. Oxford: Oxford University Press, 1982

[11] Kress. Gunther, Multimodality: A Social Semiotic Approach to Contemporary Communication, N.Y.: Routledge, 2010

[12] Milal. A. Dzo'ul, Basic Course Outline for Discourse Analysis. Unpublished Document, 2016

[13] Piaget. J Piaget's theory, In Piaget and his school (pp. 1123), Berlin: Springer Berlin Heidelberg, 1976

[14] Vygotsky. L.S, Mind in Society: The development of higher psychological processes, Mass: Harvard University Press. 1978 